\title{
ENGINEERING PROPERTIES OF FRESH-WATER ICE
}

\author{
By L. W. Gold \\ (Division of Building Research, National Research Council of Canada, Ottawa, Ontario \\ KIA oR6, Canada)
}

\begin{abstract}
The principal engineering problems requiring knowledge concerning the properties of ice are prediction of the maximum force that ice might exert on a structure and determination of the load that can be placed safely on an ice cover. The properties of ice relevant to these problems are discussed. Particular attention is given to the dependence of Young's modulus on the frequency of the stress, strain-rate dependence of the yield and fracture strengths, and the ductile to brittle transition. It is shown that the strain-rate dependence of these properties is consistent with information on the stress dependence of dislocation velocity on the basal plane. The tensile and compressive strengths are also shown to be consistent with current theories of crack initiation and propagation.

RÉsumé. Propriétés de la glace d'eau douce en génie civil. Les principaux problèmes de génie civil requérant des connaissances sur les propriétés de la glace sont la prévision des efforts maximaux que la glace peut exercer sur une structure et la détermination de la charge que l'on peut faire supporter en sécurité par une couverture de glace. On discute les propriétés de la glace à l'égard de ces problèmes. On accorde une attention particulière à l'influence de la fréquence des efforts subis sur le module de Young, à l'influence de la vitesse de déformation sur les limites d'écoulement et les efforts de rupture, et sur le passage de la zone plastique à la zone cassante. On montre que l'influence de la vitesse de déformation sur ces propriétés est en accord avec ce que l'on sait de l'influence des contraintes sur la vitesse des dislocations sur le plan de base. On montre aussi que les résistances à la traction et à la compression sont en accord avec les théories courantes sur la production et la propagation des fentes.

Zusammenfassung. Bautechnische Eigenschaften von Süsswassereis. Die wichtigsten ingenieurtechnischen Probleme, die eine Kenntnis der Eigenschaften des Eises erfordern, sind die Vorausberechnung der maximalen Beanspruchung, die Eis auf ein Bauwerk ausüben kann, und die Bestimmung der Last, die ohne Gefahr auf eine Eisdecke gebracht werden kann. Die für diese Probleme bedeutsamen Eigenschaften des Eises werden diskutiert. Besondere Beachtung findet die Abhängigkeit des Youngschen Moduls von der Frequenz der Spannung, die Abhängigkeit zwischen Verformungsrate und Fliess- und Bruchfestigkeit sowie der Übergang von der Elastizität zur Sprödigkeit. Es wird gezeigt, dass die Abhängigkeit dieser Eigenschaften von der Verformungsrate übereinstimmt mit der Kenntnis der Spannungsabhängigkeit der Versetzungsgeschwindigkeit in der Basisebene. Ebenso wird die Konsistenz der Zug- und Druckfestigkeit mit den gängigen Theorien der Rissbildung und -fortpflanzung nachgewiesen.
\end{abstract}

\section{INTRODUCTION}

Engineering is defined as the art and science concerned with the application of scientific knowledge. In recent years there has been increasing exploration, development and construction in areas where ice is a major factor. This activity is providing challenging opportunities not only for the application of scientific knowledge concerning ice but also for the extension of our understanding of the behaviour of this unique material.

There are two challenging engineering problems that require information on ice. These are the estimation of the maximum force that ice might exert on a structure and the determination of the maximum load that can be carried safely by an ice cover. Other problems, such as the rate of closing of cavities and the stability of large ice bodies that are a potential threat to human activity, require consideration from time to time. All these problems involve the deformation and strength of ice, and it is the properties that determine this behaviour that are of particular interest to the engineer.

Considerable attention has been given to the deformation behaviour of ice in glaciers and ice sheets. As a result, there is now a relatively good appreciation of the stress and temperature dependence of the creep of granular ice for stress less than $2 \mathrm{MN} \mathrm{m}^{-2}$ and in the range of strain associated with the secondary creep rate (Glen, I975; Weertman, I973). This is not, however, the information required for most engineering problems. The ranges of stress, strain and strain-rate of interest to the engineer are usually quite different from those for glaciers, and the ice involved can be of a variety of structural types with grain shape varying from granular to tabular to columnar. 
It is instructive to consider the ranges of stress, strain and strain-rate associated with the principal problems. Bearing capacity determinations can be for moving or stationary loads. If the load is travelling at $\mathrm{I} \mathrm{km} \mathrm{h}^{-1}$, the time during which an ice cover $\mathrm{I} \mathrm{m}$ thick is subject to significant stress is less than $200 \mathrm{~s}$. Recent observations on the elasticity of ice show that even for this slow speed of travel, an ice cover can be assumed to respond elastically (Traetteberg and others, 1975). With this assumption the determination of the load that can be placed safely on a good quality ice cover is relatively straightforward if the maximum allowable tensile stress can be specified. Observations reported by Gold (I97I) on the use of ice covers by moving loads indicate that this stress is about $\mathrm{I} \mathrm{MN} \mathrm{m}^{-2}$.

There is still discussion concerning the criterion of performance that should be applied for stationary loads on ice covers. One that is reasonable and practical is that the deflection should not exceed the available freeboard. This will ensure that water will not appear on the ice surface, an event that can have a psychological impact as well as result in freezing-in of material and equipment. With this criterion of performance, the maximum strain in the ice will be less than $0.5 \%$, even for ice $2 \mathrm{~m}$ thick (Frederking and Gold, 1976). Loads are left on the ice covers for periods of from less than a day to several months. Maximum rates of strain, therefore, lie in the range of $10^{-6}$ to ${ }^{1} 0^{-9} \mathrm{~s}^{-1}$. The maximum stress is less than I $\mathrm{MN} \mathrm{m}^{-2}$, but the strain is confined to the primary creep range.

For the ice pressure problem, a structure must have sufficient strength so that if there is significant movement of the ice with respect to it, the ice will fail. Stresses, therefore, are greater than $2 \mathrm{MN} \mathrm{m}^{-2}$ and usually develop under conditions approaching constant rate of strain. The rates of strain of interest are greater than $10^{-7} \mathrm{~s}^{-1}$ and in the range associated with the ductile to brittle transition for ice, or with brittle behaviour. When extreme forces occur they usually do so relatively rapidly and are associated with crushing, buckling, splitting or failure in bending.

In this review, attention will be given primarily to those properties that determine the strength and deformation behaviour of polycrystalline ice for ice pressure and bearingcapacity problems. There is, at present, a wide scatter in the measured values for many of these properties, which is indicative of both the nature of the material and the conditions of measurement. There is also considerable uncertainty concerning the relationship between measured values and the effective values for a given field situation or those which should be assumed for design purposes. Particular attention will be given to current knowledge that provides some appreciation of the reasons for the scatter and for the uncertain relationship between measured values and those appropriate for engineering applications.

\section{MODES OF DEFORMATION}

At temperatures of interest to the engineer, polycrystalline ice is an elastic-visco-plastic solid. Each grain is anisotropic with respect to its elastic properties. It has now been amply demonstrated that it is also anisotropic with respect to its viscous and plastic behaviour; the shearing resistance of non-basal planes being a factor of more than ten greater than that of the basal planes (Higashi and others, 1968).

When a grain in polycrystalline ice is forced to undergo a constant-volume change in shape and the stress is not parallel or perpendicular to its axis of crystallographic symmetry, it does so primarily by slip on basal planes and rotation about low-angle boundaries that form perpendicular to them (Gold, 1972[a]). Accommodation that must take place between grains during ductile deformation does so primarily in the grain-boundary regions. Here, evidence is found of grain-boundary migration, polygonization and void formation. With continued deformation this region of major distortion grows until it consumes the adjacent grains. If the stress is sufficiently high, this process is accompanied by the formation of internal cracks. It is clear that visco-plastic deformation of ice is associated with structural changes that can have a significant effect on its properties. 
Transmission electron microscopy has shown that slip on the basal plane is associated with the stress-induced motion of dislocations (Fukuda and Higashi, I973). Grain boundaries are potential barriers for dislocations, and can be expected to cause the formation of pile-ups. The stress near the head of a pile-up is directly proportional to the effective shear stress acting on it and to $(l / r)^{\frac{1}{2}}$ where $l$ is the length of the pile-up and $r$ is the distance from the head to the point where the stress is being determined. It can be appreciated that during ductile deformation, the stress concentrations at such sites can become quite large and be responsible for the initiation of other modes of deformation, such as grain-boundary migration, climb of dislocations out of their slip planes and the formation of cracks. If the rate of change in shape of a grain is controlled by processes occurring primarily in the grain-boundary regions (e.g. climb or slip on non-basal planes) the effective stress acting on the pile-ups will approach the resolved shear stress on the basal plane.

The contribution to the strain-rate by the movement of dislocations is given by:

$$
\dot{\epsilon}=\alpha \rho_{\mathrm{m}} b \bar{v},
$$

where $\dot{\epsilon}$ is the strain rate, $\mathrm{s}^{-1}, \rho_{\mathrm{m}}$ the density of mobile dislocations, $\mathrm{m}^{-2}$, a function of stress and strain, $b$ the Burgers vector of the mobile dislocations $=4.5 \times 10^{-10} \mathrm{~m}, \bar{v}$ the average velocity of the dislocations, and $\alpha$ a geometric factor. Observations of the yield behaviour of ice single crystals subject to constant rate of strain have shown that it in agreement with the model presented by Johnston (1962) (Higashi, I967; Jones and Glen, 1969). Yield is attributed in this model to an increase in the dislocation density with deformation and the stress dependence of the average dislocation velocity. The resistance to deformation of polycrystalline ice is appreciably greater than that for slip on the basal planes of single crystals, and yield for it appears to be assoziated with the initiation and development of other modes of deformation, particularly internal crack formation for stress greater than $\mathrm{I} \mathrm{MN} \mathrm{m}^{-2}$ (Gold, 1972[a]; Carter and Michel, I971).

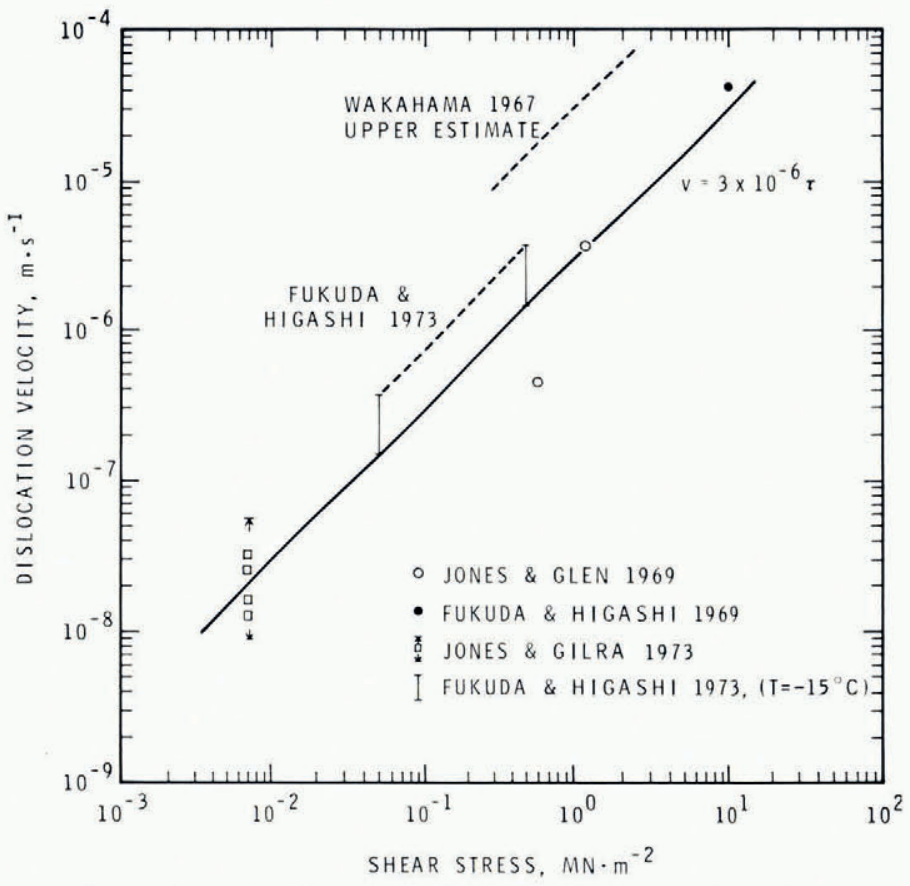

Fig. I. Stress dependence of the dislocation velocity on the basal plane. 
The information published on the stress dependence of the velocity of dislocations in ice is presented in Figure 1. These observations indicate that this dependence is given, approximately, by:

$$
\bar{v}=\left(3 \times 10^{-6} \mathrm{~m}^{3} \mathrm{~s}^{-1} \mathrm{MN}^{-1}\right) \tau,
$$

where $\tau$ is the shear stress acting on the dislocation. Equations ( 1 ) and (2) show that the greater the imposed rate of strain the larger must be the stress acting on mobile dislocations and, therefore, the greater the probability of crack formation and yield or fracture because of this activity.

If it is assumed that a typical grain dimension in the basal plane is about $2 \times 1 \mathrm{I}^{-3} \mathrm{~m}$ and the stress dependence of the dislocation velocity is given by Equation (2), then it would take about $300 \mathrm{~s}$ for a dislocation to travel from the centre of the grain to a boundary under a shear stress of $\mathrm{I} \mathrm{MN} \mathrm{m}^{-2}$. It would not be expected, therefore, that many dislocations would be forced out of their glide plane during the first $\mathrm{i}$ oo $\mathrm{s}$ of deformation for applied stress less than $2 \mathrm{MN} \mathrm{m}^{-2}$. Traetteberg and others (1975) found that for this condition ice is essentially elastic in the sense that when the load is applied for less than $100 \mathrm{~s}$, practically all the strain is recovered after the removal of the stress.

Polycrystalline ice can be expected to fail in a brittle manner when the strain-rate exceeds about $\mathrm{IO}^{-3} \mathrm{~s}^{-1}$. The unconfined compressive strength at this rate of strain is about $10 \mathrm{MN} \mathrm{m}^{-2}$. A typical value of Young's modulus for this rate of strain is $7 \times 10^{3} \mathrm{MN} \mathrm{m}^{-2}$. Assuming that the shear stress on a dislocation increases linearly from o to $5 \mathrm{MN} \mathrm{m}^{-2}$ during loading, the distance travelled by a dislocation during the time to failure, according to Equation (2), is about $\mathrm{IO}^{-5} \mathrm{~m}$ and appreciably less than typical grain dimensions in the basal plane.

The foregoing discussion indicates the importance of an appreciation of the elastic, viscous and plastic properties of ice for engineering problems. Much of the behaviour of interest to engineers occurs over a range of strain-rate for which, at the low end, polycrystalline ice is quite ductile, particularly at temperatures greater than $-20^{\circ} \mathrm{C}$, and at the high end it is brittle. It is clear that the time, stress and temperature dependence of viscous processes, both on active slip planes and in grain-boundary regions and the effect of these processes on the deformation behaviour (e.g. yield, crack formation), play a controlling role in this transformation in behaviour.

\section{Elastic MODULi}

The foregoing discussion, as well as laboratory measurements, indicates that ice can be assumed to respond elastically to stress when the period of application of the load is less than Ioo $\mathrm{s}$ for stress less than I MN m${ }^{-2}$ (Traetteberg and others, I975) or if loaded to failure within about $2 \mathrm{~s}$. Most bearing-capacity problems for moving loads, and many ice-structure interaction problems, including ice breaking, satisfy these conditions. Knowledge concerning the elasticity of polycrystalline ice is not, however, very well developed.

It is known that the elastic moduli depend upon several factors, including temperature, density, ice type, purity, time or frequency of stress, and direction of application of the load. There is evidence that they may depend also upon grain size and stress history. Figure 2 presents information that has been published on the frequency dependence of Young's modulus for polycrystalline ice at $-10^{\circ} \mathrm{C}$. This information divides naturally into three regions: the frequency range below about $10 \mathrm{~Hz}$, which is the range presently covered by hydraulic and mechanical testing machines; the range from about $10^{2}$ to $10^{4} \mathrm{~Hz}$ associated with the natural period of vibration of ice rods and propagation of seismic-type disturbances in ice covers or large ice bodies; and the range above about $10^{5} \mathrm{~Hz}$ associated with measurements using ultrasonic pulse techniques. A significant gap exists between about IO $^{2} \mathrm{IO}^{2} \mathrm{~Hz}$, a very difficult range in which to make measurements. 


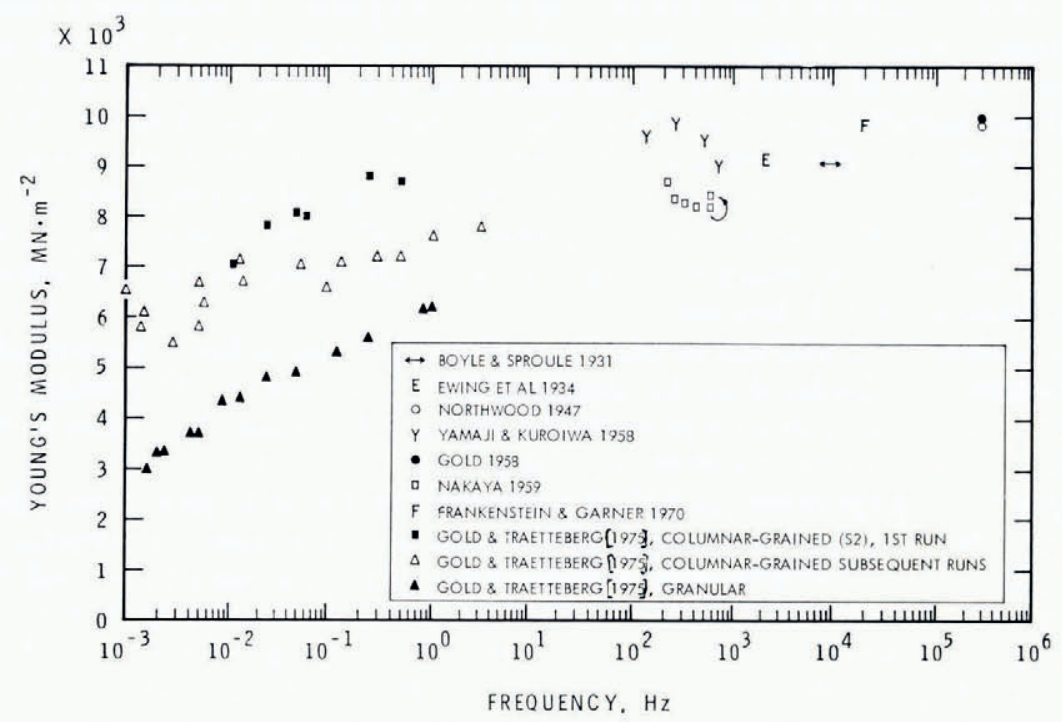

Fig. 2. Frequency dependence of Young's modulus for polycrystalline ice at $-10^{\circ} \mathrm{C}$.

It can also be seen from Figure 2 that Young's modulus increases with frequency at the low frequency range, tending to the values measured in the range $\mathrm{IO}^{2}$ to $\mathrm{IO}^{4} \mathrm{~Hz}$. Observations on the energy loss during cyclical stressing as well as a comparison of polycrystalline and singlecrystal values of the elastic moduli, indicate that the frequency dependence in this region is due to relative movement between grains in the grain-boundary region (Yamaji and Kuroiwa, 1956; Gold, I958; Nakaya, 1959; Kuroiwa, 1964). Kuroiwa has shown that this effect is dependent on the grain-boundary area and the impurity content of the ice.

Both Yamaji and Kuroiwa, and Nakaya, observed a decrease in Young's modulus with increasing frequency in the frequency range of about 200 to $600 \mathrm{~Hz}$. This is somewhat unusual, as the modulus would normally be expected to either remain constant or increase with frequency. Nakaya did report that the modulus of his samples increased after a rest period of about $12 \mathrm{~h}$. This is shown in Figure 2 by the arrow between the two points plotted at about $575 \mathrm{~Hz}$. The results of Yamaji and Kuroiwa are sufficiently consistent, however, to be corisidered as strong evidence that the decrease is real. Nakaya's observations on the change in Young's modulus with time, and a change observed between the first and subsequent sets of measurements for a columnar-grained specimen in the frequency range below io $\mathrm{Hz}$ (see Fig. 2) do show, however, that the elastic moduli are sensitive to structural changes that occur during and subsequent to the application of load cycles.

The factors controlling the frequency dependence of the elastic moduli also affect their temperature dependence at a given frequency. Gold (1958) and Ramseier (unpublished) found a marked temperature dependence for Young's modulus between $0^{\circ} \mathrm{C}$ and $-40^{\circ} \mathrm{C}$ for rate and duration of stress application equivalent to a frequency of stressing of less than $\mathrm{I} \mathrm{Hz}$. This dependence is not observed for single-crystal ice stressed parallel or perpendicular to the basal plane. The behaviour is consistent with the hypothesis that deformation in the grainboundary region contributes significantly to the strain for frequency of stressing less than about $\mathrm{IO}^{2} \mathrm{~Hz}$.

Observations on polycrystalline ice in the frequency range from $10^{2}$ to $10^{3} \mathrm{~Hz}$, show a maximum energy loss at $0^{\circ} \mathrm{C}$, decreasing to a minimum between about $-10^{\circ} \mathrm{C}$ to $-30^{\circ} \mathrm{C}$, and increasing to a second maximum at a lower temperature. The actual positions of the 
minimum and maximum depend on both frequency and purity (Yamaji and Kuroiwa, 1956; Kuroiwa, 1964). Kuroiwa gives evidence that the first maximum in the internal friction below about $-30^{\circ} \mathrm{C}$ is associated with a simple energy-loss process having a single relaxation time. Good correspondence was found between the temperature dependence of the mechanical relaxation and that for the dielectric relaxation for the same frequency of excitation (i.e. about $300 \mathrm{~Hz}$ ) indicating that this maximum in the internal energy loss is associated with the movement of proton defects in the ice crystal lattice. VanDevender and Itagaki (1973) argue from observations on the mechanical energy loss for single-crystal ice that the maximum also involves the movement of dislocations.

There is evidence of additional internal energy loss maxima at lower temperatures, which should correspond to relaxations in the elastic moduli at frequencies of stressing greater than $1^{3} \mathrm{~Hz}$ at $-10^{\circ} \mathrm{C}$. The information presented in Figure 2 shows that these changes for Young's modulus amount to probably less than $10 \%$ of its value at ${ }_{10}^{2} \mathrm{~Hz}$.

The dependence of the elastic moduli of polycrystalline ice on frequency of cyclic stressing, temperature, density, ice type, grain size, quality of the ice, and history of stressing, is still very imperfectly understood. From an engineering point of view, it would be reasonable to assume that for frequency of cyclic stressing greater than about $10^{3} \mathrm{~Hz}$, the moduli could be considered to be independent of frequency and probably independent of temperature. For the frequency range below $1^{2} \mathrm{~Hz}$, however, both the frequency and temperature dependence may often have to be taken into consideration. Measurement of the temperature and frequency dependence of the moduli provides a potentially powerful technique for investigating the behaviour and influence of defects in the ice crystal structure, including grain boundaries, and for obtaining a measure of the quality of ice.

Engineering problems for which the frequency of stressing is less than ro $\mathrm{Hz}$ are often associated with one cycle of load and an indefinite period until the next (e.g. the bearingcapacity problem for moving loads). It may be more appropriate for these cases to consider the dependence of the elastic moduli on strain-rate rather than frequency. Gold and Traetteberg ([1975]) found from experiments for which the load was applied at essentially a constant rate to a maximum stress of about $0.5 \mathrm{MN} \mathrm{m}^{-2}$, and immediately removed at the same rate, that the relaxation in Young's modulus for granular and columnar-grained (type S2) ice stressed perpendicular to the long direction of the grains, occurred over the same range in strain-rate as the ductile to brittle transition.* They also found that the relaxation processes involved were not simple, and that the relaxation time increased with time of loading raised to the power of $2 / 3$. It would appear that the strain-rate or frequency dependence of the elastic moduli of polycrystalline ice below $10^{2} \mathrm{~Hz}$ is intimately related to the processes responsible for its yield and transition from a ductile to a brittle mode of behaviour.

Observations of Poisson's ratio for polycrystalline ice also provide evidence for deformation in the grain-boundary region contributing to the strain for frequency of stressing less than Io $\mathrm{Hz}$. Sonic measurements give a value of about 0.30 for the ratio. Measurements at low rate of stressing (load cycle completed in $5 \mathrm{~s}$ to $10 \mathrm{~s}$ ) showed that for this condition Poisson's ratio does not remain constant but increases with strain (Gold, I958, 1959). The ratio is probably dependent on the strain, strain-rate, grain structure, and stress geometry at low frequencies of stressing.

\section{FAILURE}

The bearing-capacity and ice-pressure problems require information on the strength of ice for given conditions of both stress and material. For the stress levels that are of concern, failure is preceded by or due to the formation of cracks either at the surface or in the interior. Considerable information has been obtained in recent years on the characteristics of crack

\footnotetext{
* Type S2 ice (Michel and Ramseier, 197I) has the basal planes of each grain tending to be in its long direction.
} 
formation in ice and the role that it plays in failure (Carter and Michel, I97 I H Hawkes and Mellor, I972; Gold, 1972[a], [b]). Initiation and propagation of cracks are found to depend on stress, strain, strain-rate, temperature, grain structure, grain size, shape of the body, and how the load is applied, and so it is not surprising that there is a large variation in reported values of the strength and a large measure of empiricism associated with strength or load calculations.

\section{Tensile STREngth}

Fracture is usually the mode of tensile failure for polycrystalline ice at the stress levels of engineering interest. For this condition, failure is essentially brittle. The brittle tensile strength is almost independent of temperature for strain-rates greater than about $10^{-5} \mathrm{~s}^{-1}$. For uniaxial stress applied to granular ice, average grain size about $\mathrm{I} \mathrm{mm}$, temperature $-10^{\circ} \mathrm{C}$, its value is about $2 \mathrm{MN} \mathrm{m}^{-2}$ and for columnar-grained ice with the stress perpendicular to the long direction of the grains, about $\mathrm{I} \mathrm{MN} \mathrm{m}^{-2}$ (Carter and Michel, I97I). Hawkes and Mellor (1972) observed a small strain-rate dependence for granular ice at $-7^{\circ} \mathrm{C}$ with a maximum in the strength at a strain-rate of about $1 \mathrm{O}^{-3} \mathrm{~s}^{-1}$.

Gold ( $1972[\mathrm{a}],[\mathrm{b}]$ ) found that the formation of transcrystalline cracks during ductile deformation of ice is consistent with models of crack initiation based on dislocation pile-ups, such as that by Smith and Barnby (1967). A criterion for initiation derived by them is:

$$
\tau_{\mathrm{e}} \geqslant\left[\frac{3 \pi \gamma G}{8(\mathrm{I}-\nu) l}\right]^{\frac{1}{2}}
$$

where $\tau_{\mathrm{e}}$ is the effective shear stress acting on a pile-up of length $l, G$ is shear modulus, $\nu$ is Poisson's ratio, and $\gamma$ is the energy associated with the formation of new surface.

If it is assumed that $l$ is one-half the average grain diameter and equal to $\mathrm{I} \mathrm{mm}$;

$$
\begin{aligned}
\gamma & =0.1 \mathrm{~J} \mathrm{~m}^{-2} \quad(\text { Ketcham and Hobbs, } 1969), \\
G & =2.3 \times \mathrm{Io}^{3} \mathrm{MN} \mathrm{m}^{-2}, \\
\nu & =0.35
\end{aligned}
$$

then $\tau_{\mathrm{e}}=0.65 \mathrm{MN} \mathrm{m}^{-2}$. This would correspond to an applied uniaxial stress of about 1.3 $\mathrm{MN} \mathrm{m}^{-2}$ which is in reasonable agreement with the minimum stress at which cracks are observed to form in ice (about $0.6 \mathrm{MN} \mathrm{m}^{-2}$ for columnar-grained ice, average grain diameter about $3 \mathrm{~mm}$ (Gold, I972[a])).

Because of the characteristics of crack initiation and propagation, ice under stress can be in a "metastable" state; that is, in a stress state for which fracture would occur if a large enough crack or flaw were present. The crack that is initiated by a stress concentration such as a dislocation pile-up will have a size that is determined by the local strain energy. It will be a stable, non-propagating crack if it is not sufficiently big to be propagated by the applied stress.

For columnar-grained ice, it is reasonable to assume for a uniaxial tensile stress that the crack of critical size for propagation under the applied stress would be long and narrow and subject to the condition of plane stress. The criterion for its propagation is given by:

$$
\sigma_{\mathrm{f}}=\left[\frac{2 E \gamma_{\mathrm{p}}}{\pi c}\right]^{\frac{1}{2}}
$$

where $\sigma_{\mathrm{f}}$ is the tensile stress, $E$ is Young's modulus, $2 c$ is the crack width, and $\gamma_{\mathrm{p}}$ is the surface energy $\left(0.1 \mathrm{~J} \mathrm{~m}^{-2}\right.$ ) plus the work associated with viscous or plastic deformation during propagation (see Tetelman and McEvily, r967).

There is little information available on $\gamma_{p}$ for ice. Observations by Gold ( 1963 ) on crack formation by thermal shock indicate that it is not too different from $\gamma$, the surface energy. This is consistent with the observation that formation of cracks in ice during creep or constant strain-rate tests has the characteristics of a brittle event. 
If it is assumed for columnar-grained ice that $\sigma_{\mathrm{f}}=\mathrm{I} \mathrm{MN} \mathrm{m}^{-2}, E=7 \times 1 \mathrm{I}^{3} \mathrm{MN} \mathrm{m}^{-2}$, $\gamma_{\mathrm{p}}=0.9 \mathrm{~J} \mathrm{~m}^{-2}$, then Equation (4) gives $2 c=0.9 \mathrm{~mm}$ and for $\sigma_{\mathrm{f}}=0.6 \mathrm{MN} \mathrm{m}^{-2}$, $2 c=2.5 \mathrm{~mm}$.

These values, which are of the same order as the grain size, are the smallest crack widths that would result in fracture at the respective uniaxial tensile stresses. Trans-crystalline cracks of this size are observed to form in columnar-grained, $\mathrm{S}_{2}$ ice during uniaxial compressive creep for the same stresses (Gold, 1972[a]). The strain to the formation of the first cracks of this size is about $\mathrm{IO}^{-3}$ and $5 \times 1 \mathrm{O}^{-3}$ respectively.

For granular ice it would be reasonable to assume that the critical crack would be "pennyshaped". The criterion for its propagation is given by:

$$
\sigma_{\mathrm{f}}=\left[\frac{\pi E \gamma_{\mathrm{p}}}{2 c\left(\mathrm{I}-\nu^{2}\right)}\right]^{\frac{1}{2}},
$$

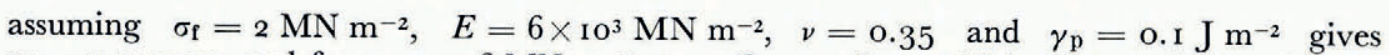
$2 c=0.54 \mathrm{~mm}$, and for $\sigma_{\mathrm{f}}=0.6 \mathrm{MN} \mathrm{m}^{-2}, 2 c=6 \mathrm{~mm}$. It would be expected that the size of a dislocation crack would be normally limited to about the grain size. Observations by Hawkes and Mellor (1972) on the tensile strength of granular ice of average grain size $0.7 \mathrm{~mm}$ are consistent with the above calculations. They found that for uniaxial tensile stress less than about I $\mathrm{MN} \mathrm{m}^{-2}$, the maximum strength was associated with yield rather than fracture. They also found that the strain to fracture was less than $1 \mathrm{O}^{-3}$ and decreased with increasing strain-rate, tending to about $3 \times 10^{-4}$ for strain-rate greater than $1^{-3} \mathrm{O}^{-1}$. The foregoing calculations indicate that initiation and propagation of cracks in ice for the values of tensile stress of interest for engineering problems is consistent with current theoretical models and with an energy of formation of new surface during crack propagation that is about equal to the surface energy of ice.

A question of some interest is the time and temperature dependence of fracture. One school of thought that has received appreciable attention is that fracture is a thermally activated process (Zhurkov and Sanfirova, 1960). Such processes must play a role, for example, in the movement of dislocations into and out of pile-ups, and in their ultimate coalition to initiate a crack. But the influence of time and temperature on the fracture strength is probably not direct, but rather through their effect on the deformation processes that are responsible for the build-up of crack-induced stress concentrations. For stress greater than I $\mathrm{MN} \mathrm{m}^{-2}$ for columnar-grained, $\mathrm{S}_{2}$ ice, for example, strain to the formation of the first large crack is relatively constant and about equal to $2 \times 10^{-4}$ (Gold, $1972[\mathrm{a}]$ ). Hawkes and Mellor (1972) found the strain to tensile fracture for granular ice subject to uniaxial tension, decreased from about $6 \times \mathrm{IO}^{-4}$ at a strain-rate of $\mathrm{IO}^{-5} \mathrm{~s}^{-1}$, to about $3 \times 10^{-4}$ at a strain-rate of $\mathrm{IO}^{-3} \mathrm{~s}^{-1}$. Time to failure for both these situations would depend primarily on the strain-rate. An analysis of the temperature and stress dependence of the time to failure would, therefore, reflect the dependence of the strain-rate on these factors. Activation energies determined by Gold (1972[a]) from observations on the time to formation of first cracks did, in fact, have values that were about equal to those obtained from the temperature dependence of the strain-rate for a given stress.

Few engineering problems involve the uniaxial tensile strength of ice. Problems for which the tensile strength is important are usually associated with the vertical deflection of ice covers, and so the property of interest is the flexural strength for the biaxial stress condition associated with the bending of plates. Measurements of flexural strength of ice, however, are normally made on beams and at a rate at which the visco-elastic behaviour is significant. In calculating this strength, little attention has been given to the possible effects of crackinitiating stress concentrations at the surface of beams or to the strain-rate dependence of the elastic modulus and of the strength itself. 
It is of some interest to note that tensile strengths determined from centre-loaded simplysupported circular ice plates, for which the two in-plane principal stresses in the region of maximum stress are equal, can be appreciably greater than those obtained from uniaxial tests. The author has measured values between 3.55 and $4.55 \mathrm{MN} \mathrm{m}^{-2}$ (8 tests) for ice plates $50 \mathrm{~cm}$ in diameter and about $1.25 \mathrm{~cm}$ thick, loaded to failure within $10 \mathrm{~s}$.

\section{COMPRESSIVE STRENGTH}

Information on the strain-rate dependence of the maximum strength of various types of polycrystalline ice subject to a uniaxial compressive stress is presented in Figure 3. For the columnar-grained ice, the stress was applied perpendicular to the long axis of the columns. It can be seen that the compressive strength has a maximum at a strain-rate of between $\mathrm{IO}^{-4}$ to $\mathrm{IO}^{-3} \mathrm{~s}^{-1}$. There is still some uncertainty concerning the decrease at higher strain-rates as this is a particularly difficult region for measurements and measured values may be significantly affected by the conditions between the load platens and the ends of specimens. For lower rates of strain up to at least $10^{-5} \mathrm{~s}^{-1}$, the dependence of the yield stress on the strain-rate on a constant strain-rate test is in good agreement with the dependence of the secondary creep rate on the stress in a constant load test (see Fig. 3).

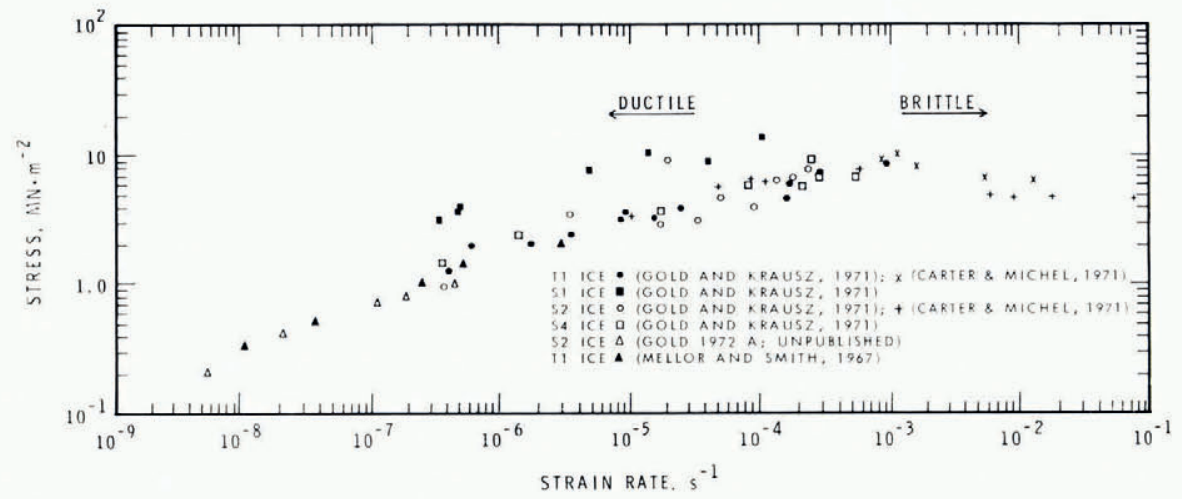

Fig. 3. Strain rate dependence of the yield and brittle strength $(\mathbf{O}, \mathrm{O}, \mathbf{\square}, \square,+, \times)$; stress dependence of secondary creep rate $(\Delta, \triangle)$.

It is of interest that the compressive strengths of columnar type $\mathrm{S}_{2}$ ice, granular ice and ice formed from frazil are about the same for a given rate of strain. Each of these ice types will have a resolved shear stress on the basal planes of most of the grains, and mobile dislocations on this plane of easy slip will be able to participate readily in the initiation and development of new modes of deformation. Columnar type $\mathrm{S}_{\mathrm{I}}$ ice, for which the basal planes are perpendicular to the long direction of the grains and, therefore, parallel to the applied stress (i.e. there is no resolved shear stress on the basal planes), has a significantly higher strength for strainrates less than $\mathrm{IO}^{-3} \mathrm{~s}^{-1}$.

Figure 4 illustrates clearly the difference that exists between the deformation behaviour of the various ice types in the ductile range. Type $\mathrm{S}_{2}$ ice has a relatively sharp yield within the first $0.5 \%$ strain. This appears to be due to a relatively rapid build-up of internal stress concentrations under the constraints associated with this particular columnar-grained structure (Gold, I972[a]). Granular ice (type $\mathrm{T}_{\mathrm{I}}$ ) and frazil ice (type $\mathrm{S}_{4}$ ) are more ductile with yields at about $\mathrm{I} \%$ strain. They also appear to be tougher, which is probably due to their granular structure, although grain size may also have an effect. Columnar-grained ice, type $\mathrm{S}_{\mathrm{I}}$, is much stronger, less ductile in its behaviour, with yield at about $0.5 \%$. 


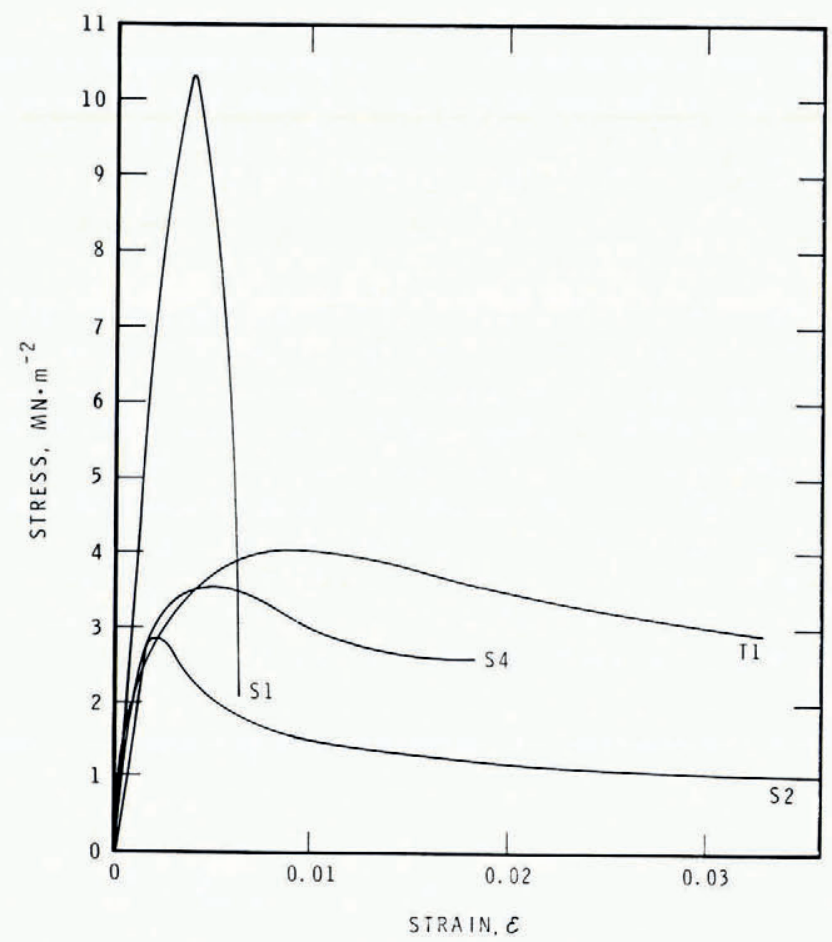

Fig. 4. Strain dependence of the stress for ice types from the St Lawrence River. Strain-rate, $1.67 \times \mathrm{IO}^{-5} \mathrm{~s}^{-1} ;$ temperature, $-9.5^{\circ} \mathrm{C}$ (Gold and Krausz, 197I).

The formation of internal cracks is an important feature for compressive yield and fracture of polycrystalline ice for uniaxial stress greater than about $\mathrm{I} .0 \mathrm{MN} \mathrm{m}^{-2}$. For maximum stresses below that value, crack formation is essentially random, indicating little interaction between cracks, and confined primarily to the primary creep or pre-yield stages. Above that value, crack formation is initially random, but usually becomes non-uniform prior to yield or failure. The pattern of the cracking activity depends on the condition of the platen surfaces and the ends of the specimens. Under certain conditions, specimens fail by axial cleavage. If the ends of the specimens are sufficiently constrained, shear failure will occur, with crack formation concentrated in zones parallel to the planes of maximum shear (Hawkes and Mellor, 1972; Gold, 1972[a]).

If a polycrystalline ice specimen is subject to biaxial rather than uniaxial compressive stress, crack formation and the time-dependent strain are suppressed in the direction of the constraining force, and the strength is modified accordingly. Figure 5 presents observations on the strength of columnar-grained type $\mathrm{S}_{2}$ ice rigidly confined in a direction perpendicular to that of the applied load (Frederking, [1972]). They clearly show the anisotropy of the strength of this ice type. The effect of constraint is minimal for granular ice which is still able to flow relatively freely in the third orthogonal direction. For the columnar-grained ice, the strength is approximately doubled if the constraining force is perpendicular to the long direction of the columns; there is little effect if it is in the long direction of the columns.

The characteristics of crack formation in ice are significant for many engineering problems involving a structure subject to a load from an ice cover. It is commonly assumed that the maximum force that can be exerted by the ice is that associated with its crushing strength as determined from uniaxial compression tests. This may be true, for example, for failure at a 


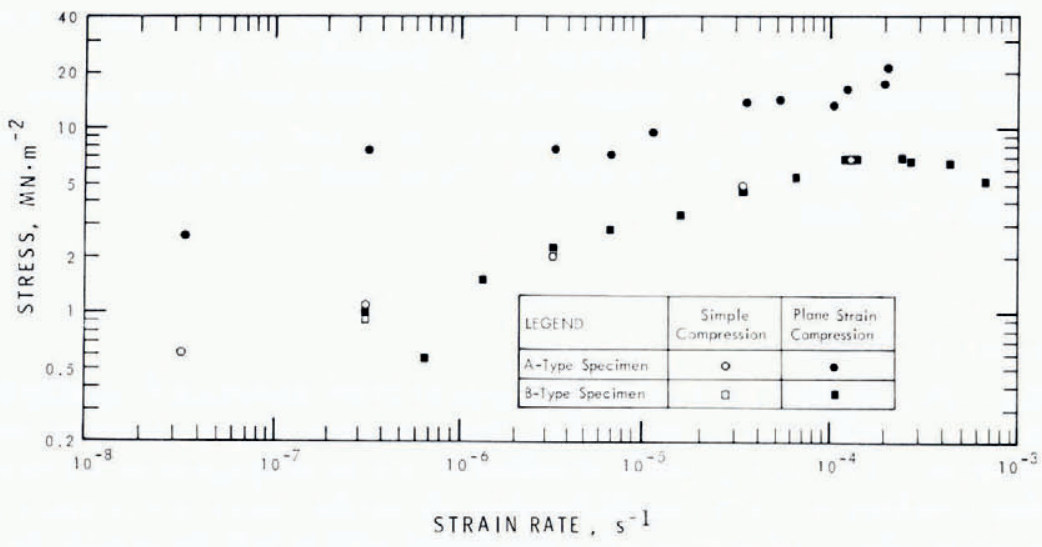

Fig. 5. Strain-rate dependence of yield and failure stress for columnar-grained type $S_{2}$ ice subject to compressive stress. For A-type specimens, applied stress and confining stress perpendicular to long direction of grains; for B-type specimens, applied stress perpendicular to long direction, confining stress parallel to it. $T=-10^{\circ} \mathrm{C}$ (Frederking, [1972]).

cylindrical structure when cracks radiating from the structure divide the ice cover into wedgeshaped pieces which then fail by a combination of shear and crushing (Croasdale, I974). Under some conditions, however, the maximum force may be determined by the formation of one or more cleavage cracks parallel to the surface of the ice subsequent to the formation of cracks normal to the surface as observed in laboratory experiments (Zabilansky and others, 1975). Hirayama and others (1974) present evidence that crack formation in the ice near a structure is constrained due to friction or adhesion between the structure and the ice. A "plastic" zone is induced in the ice adjacent to the structure and because of the lateral restraint of the surrounding ice the flow in it tends to be normal to the surface of the ice cover. They argue that the cleavage cracks are due to the tensile stresses induced by this plastic flow. This type of failure can be observed in the laboratory if the specimen is constrained in a direction perpendicular to the applied load or if there is little or no friction between the specimen and the load pattern. Information is now becoming available that, it is to be hoped, will allow the appropriate relationships to be established between the strength and deformation properties of ice measured at a laboratory scale and those that determine its behaviour when moving against a structure (Wu and others, 1974; Croasdale, 1974). As shown by $\mathrm{Wu}$ and others, the stress immediately in front of the structure depends on the width of the structure and the thickness of the ice in addition to the properties of the ice under given conditions.

Carter and Michel (I97I) found the tensile strength of polycrystalline ice to be little influenced by temperature between $0^{\circ} \mathrm{C}$ and $-40^{\circ} \mathrm{C}$ for the brittle range of behaviour. This indicates that the quantity $E_{\gamma \mathrm{p}} / c$ in Equations (4) and (5) is essentially independent of temperature. They did find, however, that the strain-rate associated with the transition is temperature dependent, decreasing with decreasing temperature and being between $1^{-6}$ and $10^{-7} \mathrm{~s}^{-1}$ at $-10^{\circ} \mathrm{C}$.

The situation is different for the compressive strength of polycrystalline ice. Failure in the ductile range in this case is associated with the deterioration of the structure through the formation of essentially non- or slowly-propagating cracks. The formation of a crack indicates that a critical condition was attained, a condition that depends on structure, relative crystallographic orientation of adjacent grains, and the relative contribution of the various modes of deformation. The latter are quite dependent on temperature. Observations by Gold (1972[b]) have shown that the number of cracks that form in a given strain for the same constant compressive stress, decreases with decreasing temperature. For tests being carried out at constant 
strain-rate, this would have the effect of causing an apparent increase in strength with decrease in temperature (Carter and Michel, I97I ; Butkovich, I954).

Compressive strength cannot be simply related to temperature. The temperature dependence also depends on the type of ice, strain-rate, and grain size. An appreciation of the factors controlling the strength of ice is only now beginning to develop. Much work on this problem has still to be done.

\section{DUGTILE TO BRITTLE TRANSITION}

A question that is of some interest to the engineer is the transition from ductile to brittle behaviour for polycrystalline ice. In tension, this transition occurs relatively abruptly, i.e. when conditions are such that a crack of sufficient size to propagate as a Griffith crack is initiated before yield occurs. This condition depends on the strain-rate, stress, temperature, ice type and grain size. The tensile stress associated with brittle behaviour for columnargrained $\mathrm{S}_{2}$ ice, average grain size $3 \mathrm{~mm}$, subject to a force perpendicular to the long direction of the grains, is about I.o $\mathrm{MN} \mathrm{m}^{-2}$ and for granular ice of average grain size about $\mathrm{I} \mathrm{mm}$, 2.0 $\mathrm{MN} \mathrm{m}^{-2}$ (see Carter and Michel, I97I ; Hawkes and Mellor, I972). Hawkes and Mellor found that although the brittle tensile strength is relatively independent of strain-rate, it does appear to have a maximum at about $10^{-3} \mathrm{~s}^{-1}$. The maximum indicates that even in the brittle range viscous flow must still be associated with fracture. Totally elastic response appears to occur only for strain-rates greater than about $\mathrm{IO}^{-1}$ to $\mathrm{I}^{-1}$. This would correspond to a rate of cyclic stressing greater than about $\mathrm{ioo} \mathrm{Hz}$.

It does appear that the apparent maximum in the brittle tensile strength occurs in the same range of strain-rate as that which would be associated with the change in Young's modulus over the frequency range of $\mathrm{IO}^{-3}$ to $100 \mathrm{~Hz}$ shown in Figure 2. The possible relationship between these two features has not yet been investigated theoretically or experimentally. This behaviour, however, is consistent with the stress dependence of the dislocation velocity. At a strain-rate of $\mathrm{IO}^{-5} \mathrm{~s}^{-1}$, a dislocation would move in granular ice about $1 \mathrm{O}^{-2} \mathrm{~cm}$ before failure, assuming the validity of Equation (2). This is appreciably less than the average grain size of fine-grained ice, i.e. about $\mathrm{o}$. $\mathrm{cm}$. Observations of the Young's modulus of granular ice indicate that it is essentially elastic to failure in tension for strain-rate equal to or greater than this value for temperature lower than about $-5^{\circ} \mathrm{C}$ (Carter and Michel, 197 I ; Hawkes and Mellor, 1972). The foregoing indicates that the ductile to brittle transition in tension occurs when the strain-rate is such as not to allow sufficient time for dislocations to contribute significantly to the strain prior to the initiation of fracture. The relative constancy of the brittle tensile strength suggests that fracture begins at sites whose effectiveness is relatively independent of the strain-rate.

The ductile to brittle transition is much more gradual for compressive stress. The initiation of a crack during the initial stage of deformation does not affect the strength significantly, but it does allow the ice in the vicinity of it to conform more easily to the imposed deformation, i.e. a form of work softening. This cracking activity must certainly be a significant factor with respect to yield for ductile behaviour and stress greater than about $\mathrm{I} \mathrm{MN} \mathrm{m}^{-2}$ (Gold, $1972[\mathrm{a}],[\mathrm{b}])$. One of the interesting features of this activity is that it appears to be composed of two independent populations; one with a probability of crack initiation directly proportional to the strain, and the second with a probability of initiation independent of the strain. The former appears to be associated with trans-crystalline cracks and is consistent with crack initiation by dislocation pile-ups; the second with grain-boundary cracks.

The two populations appear to have different dependencies on strain-rate. There is evidence that grain-boundary cracks dominate in brittle fracture (Gold, 1972[a]; Wu and others, 1974). As the majority of cracks are transcrystalline for compressive creep at stress 
below $2 \mathrm{MN} \mathrm{m}^{-2}$, there must be a transition in the characteristics of the cracking activity. This transition has yet to be explored experimentally.

The ductile to brittle transition in polycrystalline ice subject to uniaxial compression appears to be associated with this change in the characteristics of the cracking activity and their dependence on stress, strain-rate, temperature, type of ice and conditions between the load platens and the ends of the specimen. If the strain-rate is sufficiently large, enough cracks form in the loading phase, or a major cleavage crack is initiated at a site of stress concentration, such as at the specimen end, so that failure occurs before yield. For this condition the stress-strain curve is essentially linear and failure can be explosive. But even at the rate of strain of $\mathrm{IO}^{-3} \mathrm{~s}^{-1}$ at $-10^{\circ} \mathrm{C}$, time to failure is about $\mathrm{I} \mathrm{s}$, so there must be significant visco-elastic deformation. With further increase in strain-rate the deformation becomes more elastic and the strength more sensitive to pre-existing stress-raising imperfections. The decrease in strength for strain-rate greater than about $10^{-3} \mathrm{~s}^{-1}$ is very probably due to the decrease in the work of fracture because of the increased elastic behaviour of ice.

To date, most attention has been directed to the strain-rate dependence of the strength of the various types of ice. Much research is still to be done. The deformation behaviour of ice in the range of strain-rate associated with the ductile to brittle transition and its dependence on all possible factors, is still not fully understood. For example, little is known on how the cracking activity responsible for failure depends on type of ice, temperature, conditions of loading, and grain size, or how the failure process depends on the size of specimen. Little is known also about the ductile to brittle transition for biaxial and triaxial stress conditions, which are the normal conditions for field situations. The failure of ice has still to be investigated using recently developed techniques of fracture mechanics.

\section{Concluding Remarks}

This review has given attention primarily to the deformation and strength behaviour of ice, behaviour that is of particular relevance to two important ice engineering problems: ice pressure on structures and the bearing capacity of ice covers. Because of limitations of space no mention has been made of other problems of concern to engineers, such as the adhesion and build-up of ice on structures and road surfaces, frictional effects on ice surfaces, and the determination of the thickness of ice bodies including ice covers. The latter need has resulted in the recent development of techniques based on the response of ice to energy propagated in various ranges of the electromagnetic spectrum. This work is producing detailed knowledge concerning the electrical properties of ice as well as opening up new possibilities for remote sensing of the characteristics of ice covers (Page and Ramseier, 1975). The frictional behaviour of the ice surface is still not properly understood, even though it is a major factor in the sports of skating and curling and for the safety of roads and airstrips in winter. The science and art of obtaining solutions to engineering problems involving ice have still not attained an acceptable level of maturity.

\section{REFERENCES}

Boyle, R. W., and Sproule, D. O. I93I. Velocity of longitudinal vibration in solid rods (ultrasonic method) with special reference to the elasticity of ice. Canadian Journal of Research, Vol. 5, No. 6, p. 6oI-18.

Butkovich, T. R. 1954. The ultimate strength of ice. U.S. Snow, Ice and Permafrost Research Establishment. Research Paper 11 .

Carter, D., and Michel, B. I971. Lois et mécanismes de l'apparente fracture fragile de la glace de rivière et de lac. Université Laval. Faculté des Sciences. Département de Génie Civil. Section Mécanique des Glaces. Rapport S-22.

Croasdale, K. R. r 974 . Crushing strength of Arctic ice. (In Reed, J. C., and Sater, J. E., ed. The coast and shelf of the Beaufort Sea. Proceedings of a symposium on Beaufort Sea coast and shelf research. Arlington, Virginia, Arctic Institute of North America, p. 377-99.) 
Ewing, M., and others. 1934. Propagation of elastic waves in ice. Part I, by M. Ewing, A. P. Crary and A. M. Thorne. Physics, Vol. 5, No. 6, p. $165-68$.

Frankenstein, G. E., and Garner, R. 1970. Dynamic Young's modulus and flexural strength of sea ice. U.S. Cold Regions Research and Engineering Laboratory. Technical Report 222.

Frederking, R. M. W. [1972.] Preliminary results of plane strain compression tests on columnar-grained ice. (In [International Association of Hydraulic Research.] I.A.H.R. symposium. Ice and its action on hydraulic structures, Leningrad, USSR, 26-29 September 1972. [Leningrad, International Association of Hydraulic Research], [Vol. I], p. 23-27.)

Frederking, R. M. W., and Gold, L. W. 1976. The bearing capacity of ice covers under static loads. Canadian Journal of Civil Engineering, Vol. 3, No. 2, p. 288-93.

Fukuda, A., and Higashi, A. I969. X-ray diffraction topographic studies of the deformation behaviour of ice single crystals. (In Riehl, N., and others, ed. Physics of ice: proceedings of the international symposium on physics of ice, Munich, Germany, September 9-14, 1968. Edited by N. Riehl, B. Bullemer, H. Engelhardt. New York, Plenum Press, p. $239-50$.

Fukuda, A., and Higashi, A. 1973. Dynamical behaviour of dislocations in ice crystals. Crystal Lattice Defects, Vol. 4 , No. 3, p. $203^{-10}$.

Glen, J. W. 1975. The mechanics of ice. U.S. Cold Regions Research and Engineering Laboratory. Cold regions science and engineering. Hanover, N.H., Pt. II, Sect. C2b.

Gold, L. W. 1958. Some observations of the dependence of strain on stress for ice. Canadian Fournal of Physics, Vol. 36 , No. 10, p. $1265-75$.

Gold, L. W. 1959. Static and dynamic elastic constants. British fournal of Applied Physics, Vol. I I, No. I I, p. $522-23$.

Gold, L. W. 1963. Crack formation in ice plates by thermal shock. Canadian Fournal of Physics, Vol. 41, No. I0, p. $1712-28$.

Gold, L. W. 1971. Use of ice covers for transportation. Canadian Geotechnical Journal, Vol. 8, No. 2, p. I 70-81.

Gold, L. W. 1972[a]. The failure process in columnar-grained ice. Canada. National Research Council. Division of Building Research. Technical Paper No. 369 .

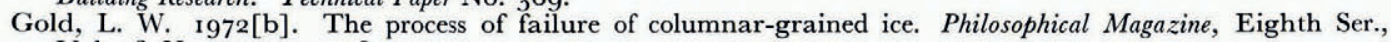
Vol. 26, No. 2, p. $311-28$.

Gold, L. W., and Krausz, A. S. I97 I. Investigation of the mechanical properties of St. Lawrence River ice. Canadian Geotechnical Journal, Vol. 8, No. 2, p. $163-69$.

Gold, L. W., and Traetteberg, A. [1975.] Young's modulus of ice and ice engineering problems. (In Weaver, D. S., ed. Proceedings. Second symposium. Applications of Solid Mechanics. June 17 and 18,1974 . Hamilton, Ontario, Faculty of Engineering, McMaster University, Vol. 1, p. 1-16.)

Hawkes, I., and Mellor, M. 1972. Deformation and fracture of ice under uniaxial stress. Fournal of Glaciology, Vol. i , No. 61, p. 103-31.

Higashi, A. I967. Mechanisms of plastic deformation in ice single crystals. (In Oura, H., ed. Physics of snow and ice: international conference on low temperature science. ... 1966. ... Proceedings, Vol. I, Pt. I. [Sapporo], Institute of Low Temperature Science, Hokkaido University, p. 277-89.)

Higashi, A., and others. I968. Strength of ice single crystals in relation to the dislocation structure, by A. Higashi, S. Mae and A. Fukuda. Transactions. Japan Institute of Metals, Vol. 9, Supplement, p. 784-89.

Hirayama, K., and others. 1974. An investigation of ice forces on vertical structures, by K. Hirayama, J. Schwarz and H. C. Wu. Iowa City, Iowa Institute of Hydraulic Research, University of Iowa. (IIHR Report No. ${ }^{8} 5^{8}$ )

Johnston, W. G. 1962. Yield point and delay times in single crystals. Journal of Applied Physics, Vol. 33, No. 9, p. $2716-30$.

Jones, S. J., and Gilra, N. K. 1973. Dislocations in ice observed by X-ray topography. (In Whalley, E., and others, ed. Physics and chemistry of ice: papers presented at the Symposium on the Physics and Chemistry of Ice, held in Ottawa, Canada, I4-18 August 1972. Edited by E. Whalley, S. F. Jones, L. W. Gold. Ottawa, Royal Society of Canada, p. 344-49.)

Jones, S. J., and Glen, J. W. 1969. The mechanical properties of single crystals of pure ice. Fournal of Glaciology, Vol. 8, No. 54 , p. $463-73$.

Ketcham, W. M., and Hobbs, P. V. 1969. An experimental determination of the surface energies of ice. Philosophical Magazine, Eighth Ser., Vol. 19, No. 162, p. 1 i6 $1-73$.

Kuroiwa, D. 1964 . Internal friction of ice. Contributions from the Institute of Low Temperature Science, Hokkaido University, Ser. A, No. 18.

Mellor, M., and Smith, J. H. 1967. Creep of snow and ice. (In Oura, H., ed. Physics of snow and ice: international conference on low temperature science. $\because$ r I966. ... Proceedings, Vol. I, Pt. 2. [Sapporo], Institute of Low Temperature Science, Hokkaido University, p. 843-55.)

Michel, B., and Ramseier, R. O. 1971. Classification of river and lake ice. Canadian Geotechnical Journal, Vol. 8, No. I, p. $3^{6-45}$.

Nakaya, U. I959. Visco-elastic properties of snow and ice in the Greenland ice cap. U.S. Snow, Ice and Permafrost Research Establishment. Research Report 46.

Northwood, T. D. 1947. Sonic determinations of the elastic properties of ice. Canadian Journal of Research, Sect. A, Vol. 25, No. 2, p. 88-95.

Page, D. F., and Ramseier, R. O. 1975. Application of radar techniques to ice and snow studies. Fournal of Glaciology, Vol. 15, No. 73, p. 171-91.

Ramseier, R. O. Unpublished. Growth and mechanical properties of river and lake ice. [Ph.D. thesis, Faculty of Science, Dept. of Civil Engineering, Laval University, Quebec, 1976.]

Smith, E., and Barnby, J. T. 1967. Crack nucleation in crystalline solids. Metal Science Journal, Vol. I, No. 2, p. $56-64$. 
Tetelman, A. S., and McEvily, A. J. 1967. Fracture of structural materials. New York, John Wiley and Sons.

Traetteberg, A., and others. 1975. The strain rate and temperature dependence of Young's modulus of ice, by A. Traetteberg, L. W. Gold and R. [M. W.] Frederking. (In Frankenstein, G. E., ed. Proceedings, third International Symposium on Ice Problems, I8-2I August 1975, Hanover, New Hampshire. [Hanover, N.H.], International Association of Hydraulic Research. Committee on Ice Problems, p. 479-86.)

VanDevender, J. P., and Itagaki, K. 1973. Internal friction of single crystal ice. U.S. Cold Regions Research and Engineering Laboratory. Research Report 243.

Wakahama, G. 1967 . On the plastic deformation of single crystals of ice. (In Oura, H., ed. Physics of snow and ice: international conference on low temperature science. . . I 1966. . . Proceedings, Vol. 1, Pt. 1. [Sapporo], Institute of Low Temperature Science, Hokkaido University, p. 291-311.)

Weertman, J. 1973. Creep of ice. (In Whalley, E., and others, ed. Physics and chemistry of ice: papers presented at the Symposium on the Physics and Chemistry of Ice, held in Ottawa, Canada, 14-18 August 1972. Edited by E. Whalley, S. F. Fones, L. W. Gold. Ottawa, Royal Society of Canada, p. 320-37.)

Wu, H. C., and others. 1974. Fracture in the compression of a brittle material-columnar grained ice, by $H$. C. Wu, K. J. Chang and J. Schwarz. Iowa City, Iowa Institute of Hydraulic Research, University of Iowa. (IIHR Report No. 23.)

Yamaji, K., and Kuroiwa, D. $1956.0^{\circ}--100^{\circ} \mathrm{C}$ no han'i ni okeru köri no nendansei. I [Viscoelasticity of ice in the temperature range o to $-100^{\circ} \mathrm{C}$. I]. Teion-kagaku: Low Temperature Science, Ser. A, [No.] 15, p. 171-83. [Translation T633, Defence Research Board of Canada, Ottawa, 1958.]

Zabilansky, L. J., and others. 1975. Ice forces on model structures, by L. J. Zabilansky, D. F. Nevel and F. D. Haynes. Canadian Journal of Civil Engineering, Vol. 2, No. 4, p. 400-1 7.

Zhurkov, S. N., and Sanfirova, T. P. I96o. Izucheniye vremennoy i temperaturnoy zavisimosti prochnosti [A study of the time and temperature dependence of mechanical strength]. Fizika Tverdogo Tela, Tom 2, No. 6, p. ro33-39. [English translation: Soviet Physics. Solid State, Vol. 2, No. 6, p. 933-38.]

\section{DISGUSSION}

D. J. Goodman: Would you like to comment on the use of the hardness test for investigating high strain-rate properties of ice under hydrostatic pressure? In a hardness test the strains are typically 0.08 (Bowden and Tabor, I964, p. 328) and for a loading time of 10 s the mean strain-rate would be $8 \times 10^{-3} \mathrm{~s}^{-1}$.

L. W. GolD: A hardness test usually involves a relatively small volume of material. In polycrystalline ice the information obtained may be more indicative of the behaviour of an individual grain than in the bulk method. Hardness tests can provide useful information on the deformation behaviour of single crystals; they are probably not too useful from an engineering point of view for obtaining information on the deformation behaviour of polycrystalline ice except for quite special problems (e.g. the problems of machining ice or drilling in it).

M. Mellor: I have a comment on the apparent maximum, or limit, of uniaxial compressive strength that occurs at about $10^{-3} \mathrm{~s}^{-1}$. In my own early work I found, like others, a maximum in strength with a slight drop off at higher rates. Ivor Hawkes convinced me that this effect was due to poor technique and together we made tests that eliminated the apparent maximum, but still showed a limiting compressive strength for high strain-rates. However Haynes is now finding higher strength values that continue to increase at high strain-rates.

GoLD: It is clear that the strength of ice is sensitive to the shape of test specimens and conditions between their ends and loading platens. With increasing rate of shear, the strength obtained must become increasingly dependent on flaws already present in the ice and other sources of elastic stress concentration. If we are to obtain a proper appreciation of the strength of ice and the factors that determine it, we are going to have to be able to determine more accurately the reasons for each initiation and propagation under particular load conditions. This includes a greater understanding of the possible role of dislocations in each initiation; the contribution of a strain-rate-dependent elastic modulus, the effects of conditions between the ice specimen and the load platens, and the nature and role of internal inherent flaws or imperfections in the specimen. 
D. V. REDDy: Would not $10^{-6} \mathrm{~s}^{-1}$ be the approximate strain-rate giving the range associated with brittle behaviour and with the ductile-to-brittle transition of ice for sea ice also?

GoLD: There is still little information on the strain-rate dependence of the strength properties of sea ice. The information that is available does indicate a transition in behaviour over about the same range in shear rate.

\section{REFERENCE}

Bowden, F. P., and Tabor, D. 1964. The friction and lubrication of solids. Part 2. Oxford, Clarendon Press. 